\title{
Adaptive landing gear: Optimum control strategy and potential for improvement
}

\author{
Grzegorz Mikułowski and Łukasz Jankowski* \\ Smart-Tech Centre, Institute of Fundamental Technological Research, Swietokrzyska 21, 00-049 Warszawa, Poland
}

Received 17 July 2007

Revised 7 March 2008

\begin{abstract}
An adaptive landing gear is a landing gear (LG) capable of active adaptation to particular landing conditions by means of controlled hydraulic force. The objective of the adaptive control is to mitigate the peak force transferred to the aircraft structure during touch-down, and thus to limit the structural fatigue factor. This paper investigates the ultimate limits for improvement due to various strategies of active control. Five strategies are proposed and investigated numerically using a validated model of a real, passive landing gear as a reference. Potential for improvement is estimated statistically in terms of the mean and median (significant) peak strut forces as well as in terms of the extended safe sinking velocity range. Three control strategies are verified experimentally using a laboratory test stand.
\end{abstract}

Keywords: Adaptive landing gear, adaptive impact absorption, shock absorber, load mitigation

\section{Introduction}

A typical, most often occurring landing scenario of an aircraft involves a relatively low sinking velocity of approx. $0.5 \mathrm{~m} / \mathrm{s}$. However, the maximum design velocity, as specified by the regulations, is usually much higher (seven to ten knots [1]) and consequently landing gears (LGs) should be designed to dissipate optimally both low-energy and high-energy landings. This is virtually impossible for a standard passive LG and thus it is optimized for the most dangerous, highest-energy landing scenario only. Therefore, in a typical landing the standard LG operates unoptimized, although well below the maximum design peak force, which nevertheless results in unnecessary high fatigue of the involved structures and shortening of their service life. The structural fatigue factor could be greatly reduced [2], if a LG was capable of adaptation to each particular landing scenario [3]. It would be then possible to optimally reduce the peak strut force in the typical low-energy landing scenarios, but also preserve the capability to dissipate rare, high-energy impacts. Such adaptive landing gear (ALG) was the goal of the project ADLAND (Adaptive Landing Gears for Improved Impact Absorption [4]), funded within the EU 6th Framework Programme.

Intensive development of landing gears started in the United States in 1950s when oleo-pneumatic design became popular and widely employed. These shock absorbers were composed of a gas spring and two hydraulic chambers separated by an orifice, which provided the resistant reaction of the hydraulic fluid. This type of shock absorber was reported to have the highest efficiency in relation to the weight [5]; however, its properties were not tunable to the wide demands of the touchdown operation. The strut reacting forces are awaited to vary in particular phases of the landing loading. Additionally, the same landing gear must also perform satisfactorily during taxi operations. Hydraulic orifices of constant geometries result in constant quadratic relation of the reaction to the velocity of the piston. It was soon determined to be beneficial to allow the hydraulic reaction to be adjustable during the operation of the strut. The first innovation to the oleo-pneumatic shock absorbers was the metering pin, which modulated

\footnotetext{
*Corresponding author. Tel.: +48 228261281 ext. 241; Fax: +48 22 8287476; E-mail: lukasz.jankowski@ippt.gov.pl.
} 
the cross-section of the orifice in dependence on the position of the piston [5]. Extensive research on the behavior of oleo-pneumatic landing gears was conducted in 1950s by NACA researchers with the objective of developing analytical modeling methods and appropriate design tools. The studies were usually conducted numerically with laboratory validation [6,7]. In parallel, the landing gears were investigated experimentally in flight tests [8]. One of the first methods to calculate the proper profile of the metering pin was proposed in [9].

Development of supersonic airplanes in 1960s introduced a new class of problems. The ground-induced dynamic and vibration problems were magnified because of increased structural flexibility of the slender bodies, thin-wing designs and higher takeoff and landing speeds. During investigations of particular designs, extremely high vibration levels of fuselages during takeoffs were reported [10]. The objectives of researches on landing gears were extended to include the effective mitigation of ground-induced vibrations. From the beginning of 1970s, an active landing gear began to be considered to be a possible solution to the vibration problems [11].

An active landing gear was defined as a shock strut with actively controlled damping force. The control amounted to increasing or decreasing the internal hydraulic pressure by means of an external reservoir of compressed medium. Initially, the researches were focused on recognition of the character of the phenomenon, analytical modelling and assessing the feasibility $[2,12]$. The first results were promising but technological problems were reported since the estimated flow rates of the hydraulic fluid were predicted to be as high as 1000 liters per minute [12]. At the beginning of 1980s the concept matured to a prototype system designed in accordance with all aeronautical regulations $[13,14]$, which was tested in impact and roll-out operations $[15,16]$. The tests showed that the device is effective in reducing the dynamics effects but also a significant bending of the landing gear during the spin-up phase of the touchdown was reported. In 1990s active landing gears were adapted for employment in military aircrafts as reported in [17-19]. Actively controlled landing gears were analyzed for military aviation also in Europe [20].

These widely studied active solutions have two important disadvantages. They are characterized by high energy consumption due to the necessity of delivering high pressures. Moreover, a fail-safe active LG is hard to realize, since characteristics of the strut air spring depends on the instantaneous amount of the oil inside the strut and, in the case of a failure, the resulting passive landing gear may be not tuned for the actual impact landing scenario. In 1990s, a new less invasive solution became to be discussed [21,22]: application of an adaptive, semi-active approach to landing gears. The hydraulic force was assumed to be controlled directly by alterations of characteristics of the main orifice of the strut. The significant advantages of the new concept are lower energy consumption (no external compressed reservoirs, no need to add hydraulic energy to the system) and better fail-safe properties. The researches were focused on optimum control development and analysis of possible actuation systems [21,23,24]. After the year 2000 , reports on experimental tests of non-flying models of adaptive landing gears become available [25,26]. The reported solutions were based on quick electric servovalves controlling the flow of the hydraulic fluid between the chambers.

Other technical solutions were proposed within the ADLAND project [4], which pursued an adaptive LG implemented using smart technologies: piezo-driven valves and magnetorheological (MR) fluids. Both approaches require a dedicated active LG head only and preserve the time-tested general design of landing gears. Piezoelectric materials are characterized by a very low power consumption, high actuation accuracy and short response time; these advantages make them perfectly suitable for a piezo-valve system for controlling the flow of hydraulic fluid in a LG. Low power consumption, mechanical reliability and simplicity of the design were important advantages of the other solution, which was based on MR fluids: an MR-based LG head is free of complicated mechanical systems and quickly moving parts, as the damping effect can be controlled directly by the magnetic flux density. In both cases, power-failure fail-safe characteristics can be easily designed by including a proper passive position of the piezo-valve or a system of magnets for the proper passive intensity of the magnetic field. The project ended in 2006 with flight test of the developed adaptive LG. Part of the design problems were presented in [27-29].

In the first stages of the ADLAND project a systematic comparison and evaluation of different control strategies was necessary, since available researches focused on a single chosen control scheme only and assumed full knowledge about the landing conditions[2,23,25,26]. This paper reports on the corresponding systematic investigation of the performance and the ultimate limits for improvement of a standard LG due to five basic strategies of adaptive control, ranging from passive to active, with and without the full information about the landing mass. As a reference, a standard oleopneumatic one-stage cantilever-type [5,30,31] passive nose LG of an I-23 light aircraft [32] is used, with no structural modifications assumed besides the possibility of an instantaneous active control. Comparison of 

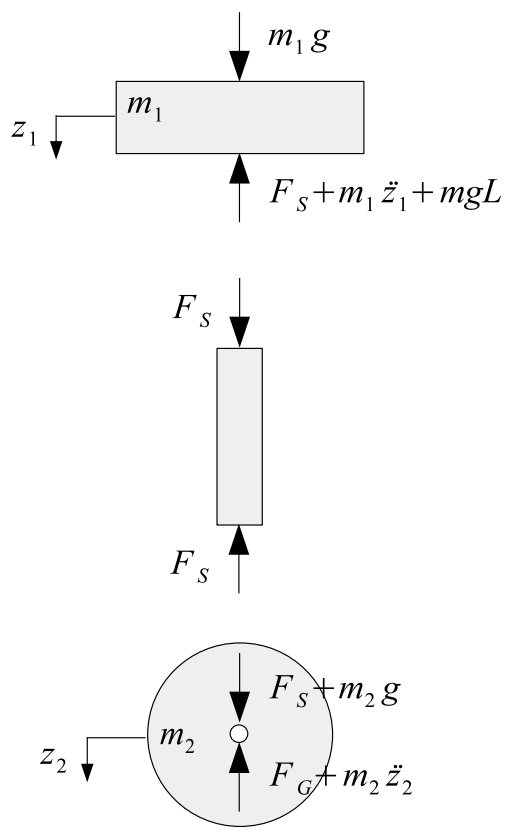

Fig. 1. Free-body diagram of landing gear (aircraft, strut and wheel).

numerical simulations with drop-tests of the reference LG confirms the accuracy of the model used for simulations. Moreover, three of the five investigated strategies are verified experimentally on a laboratory-scale drop testing stand; details of the effective real-time feedback control used in the active control schemes are reported in [27].

Optimum adaptation requires pre-touchdown recognition, at least partial, of the imminent landing scenario (mass, velocity, etc.) to trigger the adaptation in advance. This has been studied and proven feasible in [33,34]. In numerical computations, the hydraulic force is assumed here to be controlled directly by the main orifice area, which in practical implementations for ADLAND project was related to driving voltage (piezo-valve solution) or current (magnetorheological head), the latter is demonstrated also in the experimental section of the paper.

The following Section 2 states the numerical model used and validates it against measurement data. The control strategies used to minimize the peak strut force are discussed in Section 3. The potential for improvement is estimated and compared in Section 4, while Section 5 reports on the laboratory testing stand and the experimental verification.

\section{Numerical model}

For the purposes of this analysis, the (A)LG is represented by a 2 DOF system, shown schematically in Fig. 1, and modeled by the following set of equations (a modified version of the equations derived by Milwitzky and Cook in [6]):

$$
\begin{aligned}
m_{1} \ddot{z}_{1} & =m_{1} g-F_{S}-m g L, \\
m_{2} \ddot{z}_{2}= & m_{2} g+F_{S}-F_{G}, \\
z_{1}(0)= & z_{2}(0)=0 \\
\dot{z}_{1}(0)=\dot{z}_{2}(0)= & v_{0},
\end{aligned}
$$

where $m, m_{1}$ and $m_{2}$ are respectively total, upper (aircraft) and lower (wheel) masses $\left(m=m_{1}+m_{2}, m_{2}=\right.$ $8.71 \mathrm{~kg}) ; z_{1}$ and $z_{2}$ denote their vertical displacements from initial contact; $L$ denotes the lift factor $(L=0.667$ [1]); $F_{G}$ is the vertical force acting on tire at the ground; $F_{S}$ is the total axial strut force, and $v_{0}$ denotes the initial landing sinking velocity. 


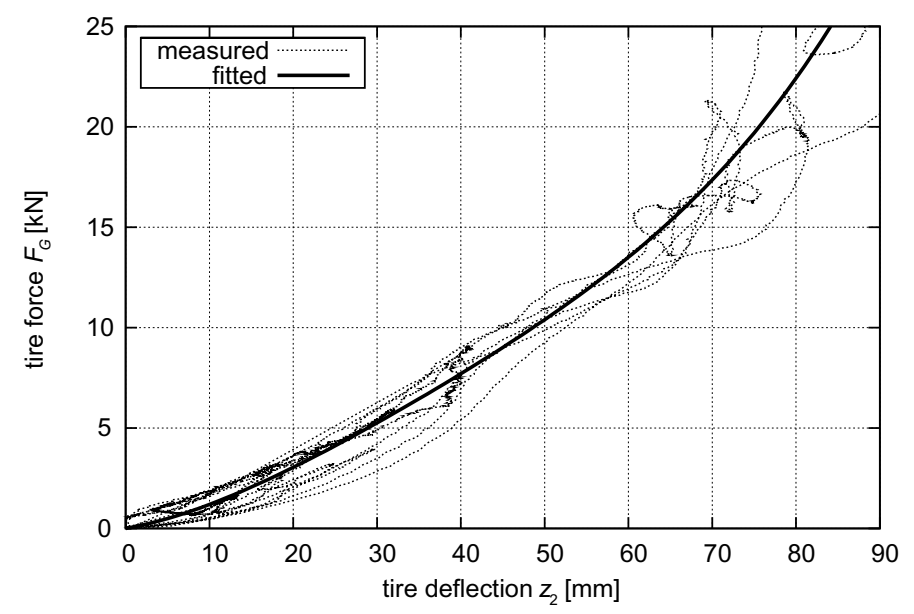

Fig. 2. Measured and fitted tire force - deflection characteristics (I-23 nose LG).

The mass $m$ and the sinking velocity $v_{0}$ are limited [32] by

$$
\begin{aligned}
288 \mathrm{~kg} & =m_{\min } \leqslant m \leqslant m_{\max }=422 \mathrm{~kg}, \\
0 \mathrm{~m} / \mathrm{s} & =v_{0(\max )} \leqslant v_{0} \leqslant v_{0(\max )}=2.93 \mathrm{~m} / \mathrm{s} .
\end{aligned}
$$

For the assumed detailed statistics of the landing mass $m$ and the sinking velocity $v_{0}$, see Section 4.2. The mass $m$ is the reduced mass (mass per landing gear) and is less than the total landing mass of the aircraft. The upper bound of $422 \mathrm{~kg}$ corresponds to the maximum I-23 design landing mass of $1117 \mathrm{~kg}$ and the lower bound of $288 \mathrm{~kg}$ was chosen to be proportional to the mass of an empty aircraft with a pilot [32].

The dynamic tire force - deflection characteristics of the I-23 nose LG, denoted in Eq. (1) by $F_{G}$, has been obtained by fitting experimental data measured in three dynamic tests (see Fig. 2). The least squares fit is a fourth-order polynomial:

$$
F_{G}\left(z_{2}\right) \approx\left(7.310^{4}+5.410^{6} z_{2}-8.610^{7} z_{2}^{2}+6.410^{8} z_{2}^{3}\right) \max \left(z_{2}, 0\right)
$$

where the last multiplier denotes symbolically that $F_{G}$ vanishes when the tire hovers above the ground.

The total axial strut force $F_{S}$ is modeled as a sum of four forces:

$$
F_{S}=F_{a}+F_{h}+F_{f}+F_{d}
$$

which are respectively strut pneumatic, hydraulic and friction forces, denoted by $F_{a}, F_{h}$ and $F_{f}$, and the delimiting force $F_{d}$, which prevents excessive strut elongation. Notice that introduction of the actually occurring delimiting force $F_{d}$ greatly simplifies modeling of the landing process, as compared to the approach of Milwitzky and Cook [6], since the LG can be uniformly modeled as a 2 DOF system throughout the whole landing, including its initial stage and - if necessary - rebounds. The total strut force and the component forces depend directly on the strut axial stroke $s$,

$$
s=z_{1}-z_{2} .
$$

The pneumatic force $F_{a}$ in Eq. (3) is modeled in accordance with the polytropic law for compression of gases,

$$
F_{a}(s)=p_{0} A_{a}\left(\frac{V_{0}}{V_{0}-s A_{a}}\right)^{n},
$$

while the hydraulic force $F_{h}$ is modeled in the standard way [6] as

$$
F_{h}(\dot{s})=\operatorname{sign}(\dot{s}) \frac{1}{2} \frac{\rho A_{h}^{3}}{C_{d}^{2} A_{o}^{2}} \dot{s}^{2} .
$$

The friction occurring in the strut is assumed to be dry friction only [6] and is modeled by 
Table 1

Symbols used in Eq. (4) to Eq. (7) [6,32,35]

\begin{tabular}{lll}
\hline Symbol & Numerical value & Explanation \\
\hline$A_{a}$ & $1.38510^{-3} \mathrm{~m}^{2}$ & Pneumatic area \\
$p_{0}$ & $1.028 \mathrm{MPa}$ & Initial air pressure in the upper chamber \\
$V_{0}$ & $1710^{-6} \mathrm{~m}^{3}$ & Initial air volume in the upper chamber \\
$n$ & 1.1 & Polytropic exponent for the air compression process \\
$\rho$ & $872.6 \mathrm{~kg} / \mathrm{m}^{3}$ & Density of hydraulic fluid (Aeroshell 41) \\
$A_{h}$ & $1.01810^{-3} \mathrm{~m}^{2}$ & Hydraulic area \\
$A_{o}$ & $A_{o(\mathrm{~min})} \leqslant A_{o} \leqslant A_{o}(\max )$ & Cross-sectional area of the discharge orifice \\
$A_{o(\min )}$ & $5 \mathrm{~mm}^{2}$ & Technological lower bound on $A_{o}$ \\
$A_{o}(\max )$ & $40 \mathrm{~mm}^{2}$ & Technological upper bound on $A_{o}$ \\
$C_{d}$ & 0.6 & Orifice discharge coefficient \\
$C_{f}$ & $559 \mathrm{~N}$ & Dry friction coefficient \\
$l_{d}$ & $50010^{-6} \mathrm{~m}$ & Delimiting force acting interval \\
\hline
\end{tabular}

$$
F_{f}(\dot{s})=C_{f} \frac{2}{\pi} \arctan \left(10^{4} \dot{s}\right)
$$

where the inverse tangent function was used to assure smooth variations of the friction force at the turning points and to enable numerical integrations of the equations of motion. The delimiting force $F_{d}$ prevents excessive elongation of the strut and attempts to model the actual force occurring on the strut delimiter. It acts within the last $l_{d}$ of the fully elongated strut and is modeled by a simple spring force as

$$
F_{d}(s)=p_{0} A_{a} \min \left(\frac{s-l_{d}}{l_{d}}, 0\right),
$$

where the coefficient $p_{0} A_{a}$ has been chosen to obtain equilibrium at full elongation: $F_{d}(0)+F_{a}(0)=0$. Possible oscillations of a fully elongated strut are damped directly by the hydraulic force $F_{h}$.

The symbols used in Eq. (4) to Eq. (7) are explained in Table 1. The numerical values of $p_{0}, V_{0}$ and of the dry friction coefficient $C_{f}$ have been obtained by numerical fitting of LG quasi-static compression data. The trimming bounds on $A_{o}$, which is the controlling parameter, are chosen arbitrarily to model real technological constraints. Notice that the following simplifying assumptions concerning the friction have been made:

- The dynamic friction equals the quasi-static friction.

- The strut friction is not considerably affected by the normal loading occurring due to tire friction in the first milliseconds of the landing process at the wheel axle. This is an oversimplification in the case of a cantilever-type LG but can be legitimate in the case of levered trailing arm gears.

Accuracy of the model can be partly verified by comparison of calculated forces and displacements with the forces and displacements measured in tests of a real I-23 nose LG, passive version. Institute of Aviation (Warsaw, Poland) has made available two sets of measurement data suitable for the comparison:

1. mass $m=422 \mathrm{~kg}$, sinking velocity $v_{0}=2.93 \mathrm{~m} / \mathrm{s}$, lift factor $L=0.667$;

2. mass $m=422 \mathrm{~kg}$, sinking velocity $v_{0}=3.52 \mathrm{~m} / \mathrm{s}$, lift factor $L=1$.

The first case corresponds to the highest-energy design landing conditions, see Eq. (2), while the second is even more demanding. Figure 3 compares the calculated and measured tire forces $F_{G}$, while Figs 4 and 5 compare the calculated and measured aircraft and tire displacements $\left(z_{1}\right.$ and $\left.z_{2}\right)$. The discharge orifice area $A_{o}$ was assumed to equal $17.43 \mathrm{~mm}^{2}$, which is the optimum value in the case of a passive LG (see Section 3.1). Simulations and measurements agree well in the case of the tire force $F_{G}$, the first $150 \mathrm{~ms}$ of tire displacement $z_{2}$ and the first $100 \mathrm{~ms}$ of aircraft displacement $z_{1}$, which corresponds to the strut compression phase. However, there is an increasing discrepancy between the displacements calculated and measured in the strut decompression phase, which starts approx. $100 \mathrm{~ms}$ after the impact. The discrepancy suggests additional factors coming into play during the strut decompression phase (possibly recoil orifices and hydraulic oil foaming), which cannot be thus modeled using a constant recoil orifice area. Nevertheless, the strut compression phase seems to be modeled reliably; hence all considerations of this paper concerning the peak strut force $F_{\text {peak }}$ and the proposed control strategies are valid. 


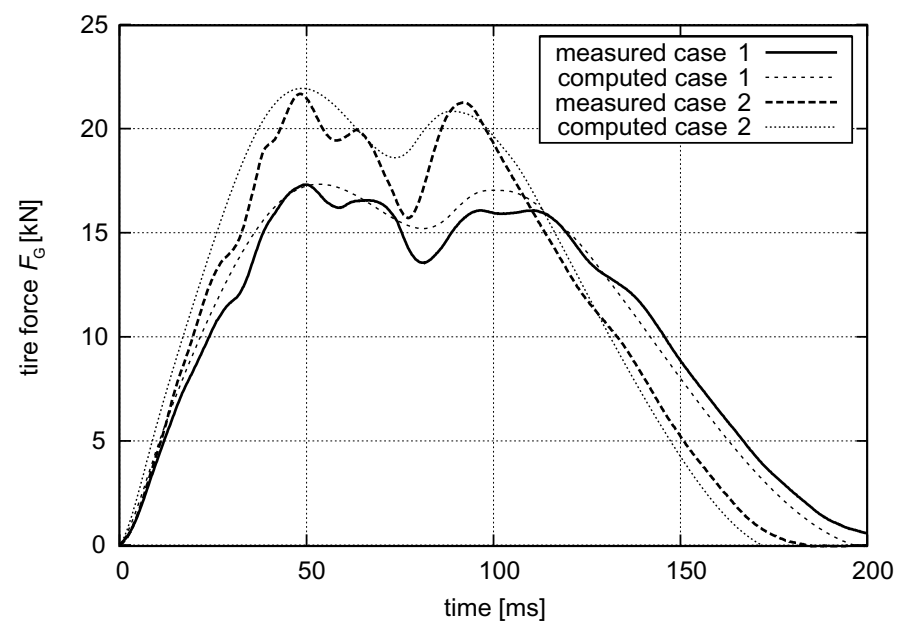

Fig. 3. Measured and computed tire force $F_{G}$, passive LG: test case $1\left(m=422 \mathrm{~kg}, v_{0}=2.93 \mathrm{~m} / \mathrm{s}, L=0.667\right)$; test case $2(m=422 \mathrm{~kg}$, $\left.v_{0}=3.52 \mathrm{~m} / \mathrm{s}, L=1\right)$.

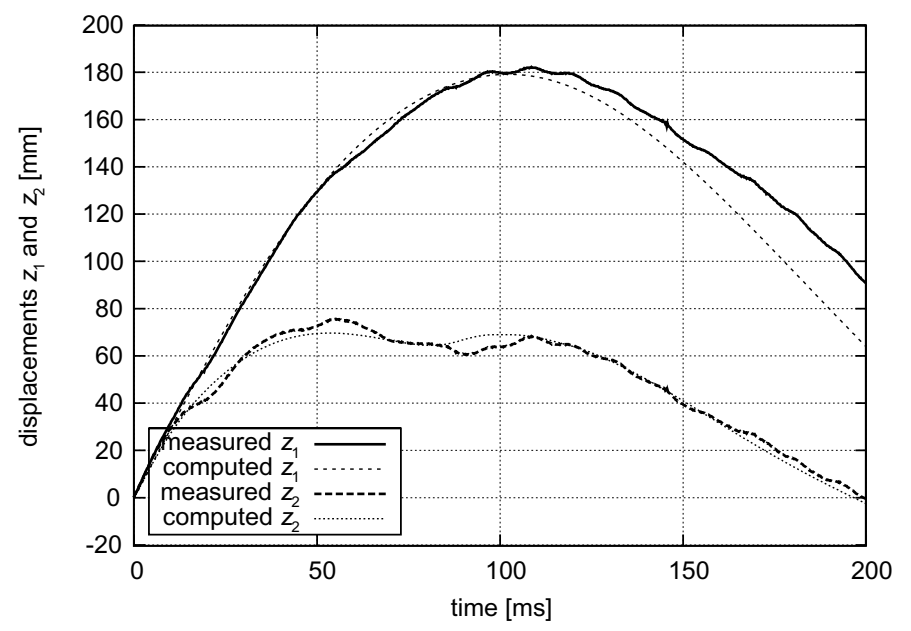

Fig. 4. Measured and computed displacements of aircraft $z_{1}$ and tire $z_{2}$, passive LG, test case $1\left(m=422 \mathrm{~kg}, v_{0}=2.93 \mathrm{~m} / \mathrm{s}, L=0.667\right)$.

\section{Control strategies}

It is assumed that the landing scenario is fully defined by two basic parameters: (1) total landing mass per strut $m,(2)$ initial strut sinking velocity $v_{0}$. Their ranges are given in Eq. (2), their distributions in Section 4.2. The common objective of all the investigated control strategies is to minimize the peak strut force $F_{\text {peak }}$ occurring during the landing. The evolution of the total strut force $F_{S}$ is fully determined by the control parameter, which is area $A_{o}$ of the discharge orifice. Essentially, there are three control strategies possible:

- Passive LG (PLG), i.e. no control. the orifice area $A_{o}$ is constant and cannot be adjusted to particular landing conditions. Nevertheless, its pre-set constant value is optimized to mitigate the peak strut force occurring at the highest-energy landing conditions (maximum design landing mass and sinking velocity).

- Semi-active LG (SLG). The orifice area $A_{o}$ is optimally set directly before each landing, based on the actual sinking velocity $v_{0}$ and/or mass $m$, which have to be measured or known in advance. $A_{o}$ remains constant during the landing process, which makes the strategy relatively easy to implement, since no quick closed control loops are necessary. 


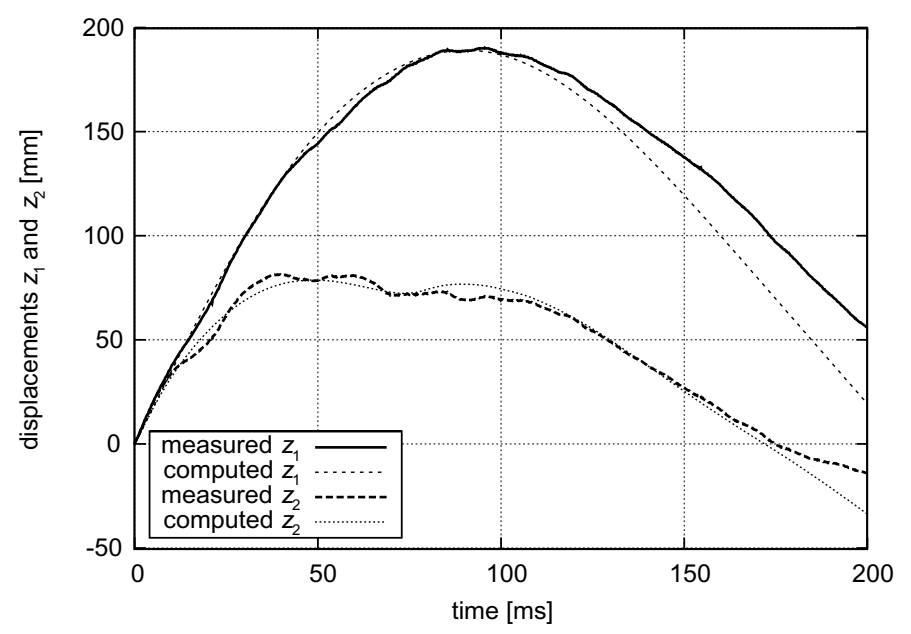

Fig. 5. Measured and computed displacements of aircraft $z_{1}$ and tire $z_{2}$, passive LG, test case $2\left(m=422 \mathrm{~kg}, v_{0}=3.52 \mathrm{~m} / \mathrm{s}, L=1\right)$.

- Active $L G$ (ALG). The orifice area $A_{o}$ changes continuously during the landing process, according to a strategy defined by the actual values of the initial sinking velocity $v_{0}$ and/or mass $m$, which have to be measured or known in advance. This strategy potentially yields the highest improvement, but requires quick closed control loops and accurate real-time measurement data, which may result in instabilities.

The strategies apply to the strut compression phase only. During the decompression phase, recoil orifices take effect instead of the main discharge orifice, the numerical model has thus to be modified and the optimization goal redefined. However, as the (to-be-minimized) peak strut force $F_{\text {peak }}$ occurs within the strut compression phase, modeling of the decompression phase is outside the scope of this paper.

To apply the active or the semi-active control strategy, as defined above, the actual landing scenario has to be at least partially known in advance. In real conditions, the sinking velocity $v_{0}$ can be relatively easy measured just before the touchdown by a dedicated sensor (e.g. ultrasonic, one per LG). However, it may not be possible to know the exact actual value of the total landing mass per strut $m$. Therefore, to asses the importance of the knowledge of the mass, altogether five cases have been considered:

1. Passive LG (PLG);

2. Semi-active LG (SLG): both $v_{0}$ and $m$ are known before landing;

3. Velocity-driven semi-active LG (VD-SLG): only $v_{0}$ is known before landing;

4. Active LG (ALG): both $v_{0}$ and $m$ are known before landing;

5. Velocity-driven active LG (VD-ALG): only $v_{0}$ is known before landing.

To investigate and assess the strategies, the equations of motion Eq. (1) had to be solved numerically, which was done with explicit methods and the time step $5 \mu \mathrm{s}$ or $50 \mu \mathrm{s}$ (active strategies). The peak strut forces computed at $5 \mu$ s and $50 \mu$ s differed by approx. $0.1 \%-0.2 \%$, which is acceptable to compare the strategies reliably.

\subsection{Passive $L G$}

The pre-set constant discharge orifice area $A_{o}^{P L G}$ has to be chosen to minimize the peak force occurring during the highest-energy design landing scenario. Figure 6 shows the dependence of the peak strut force $F_{\text {peak }}^{P L G}\left(m_{\max }, v_{0(\max )}, A_{o}\right)$ on the discharge orifice area $A_{o}$. The left slope corresponds to the decreasing peak of the hydraulic force, while the right slope corresponds to the increasing peak of the pneumatic force. The minimum value of $17021 \mathrm{~N}$ has been found at $A_{o}^{P L G}=17.43 \mathrm{~mm}^{2}$, where both peaks are equal. The corresponding computed tire peak force equals $17374 \mathrm{~N}$, which is relatively very close to the measured value of $17400 \mathrm{~N}$ (see Fig. 3). Thus, the maximum design strut force was assumed to be $F_{\max }=17021$ N. The optimum discharge orifice area for a passive $\mathrm{LG}$ is $A_{o}^{P L G}=17.43 \mathrm{~mm}^{2}$. 


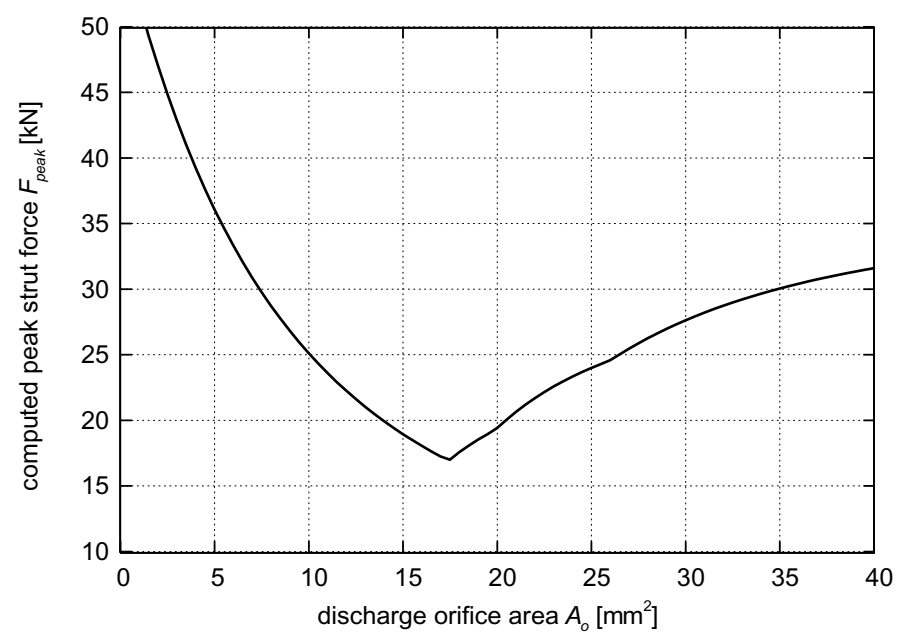

Fig. 6. Passive LG: Computed dependence of the peak strut force $F_{\text {peak }}$ on the discharge orifice area $A_{o}$ at the highest-energy design landing scenario $\left(m=422 \mathrm{~kg}\right.$ and $\left.v_{0}=2.93 \mathrm{~m} / \mathrm{s}\right)$.

$$
\begin{gathered}
F_{\max }=17021 \mathrm{~N}, \\
A_{o}^{P L G}=17.43 \mathrm{~mm}^{2} .
\end{gathered}
$$

\subsection{Semi-active $L G$}

A graph of $F_{\text {peak }}$ in dependence on the orifice area $A_{o}$ (similar to that shown in Fig. 6) can be drawn for each combination of the landing mass $m$ and the vertical velocity $v_{0}$. Therefore, if both $m$ and $v_{0}$ are known or measured just before the touchdown, the discharge orifice area $A_{o}$ can be set to the optimum value $A_{o}^{S L G}\left(m, v_{0}\right)$, within the technological bounds $A_{o(\min )}$ and $A_{o(\max )}$ (Table 1), which yields the technologically attainable minimum peak force

$$
F_{\text {peak }}^{S L G}\left(m, v_{0}\right):=F_{\text {peak }}\left(m, v_{0}, A_{o}^{S L G}\left(m, v_{0}\right)\right) .
$$

This is substantially advantageous to the passive LG, which is optimized only for the highest-energy design landing scenario.

Figure 7 shows the dependence of the computed optimum discharge orifice area $A_{o}^{S L G}\left(m, v_{0}\right)$ on the landing conditions. At standard landing conditions (low sinking velocity), the optimum orifice area $A_{o}^{S L G}$ considerably exceeds the constant value $A_{o}^{P L G}$ used in the passive LG, Eq. (8). Hence, at the same landing conditions, the peak strut force in the semi-active LG can be expected to be considerably lower than in the passive LG. The relative improvement is shown in Fig. 8, which plots the ratio of the peak force in SLG to the peak force in PLG at the same landing conditions. There is obviously no improvement in the highest-energy landing scenario, since the SLG amounts then to the PLG. The effect of the semi-active control becomes apparent as the mass or sinking velocity decreases. However, at low sinking velocities, the advantage of the SLG over the PLG tends to diminish, which is due to the effect of the initial stiffness of the air spring and the lift force: the landing energy is too low to compress considerably the strut and trigger the hydraulic force. Thus most of the vertical displacement is the tire deflection, and it is not possible to take advantage of the semi-active control scheme.

\subsection{Velocity-driven semi-active $L G$}

The semi-active control strategy requires both the landing mass $m$ and the sinking velocity $v_{0}$ to be known before landing. However, in practice only the velocity $v_{0}$ can be relatively easy measured and the mass $m$ has to be estimated. To asses the importance of the exact knowledge of the mass, the limiting case of no mass knowledge can be tested. The discharge orifice area $A_{o}$ has then to be chosen to minimize the peak strut force in the corresponding 


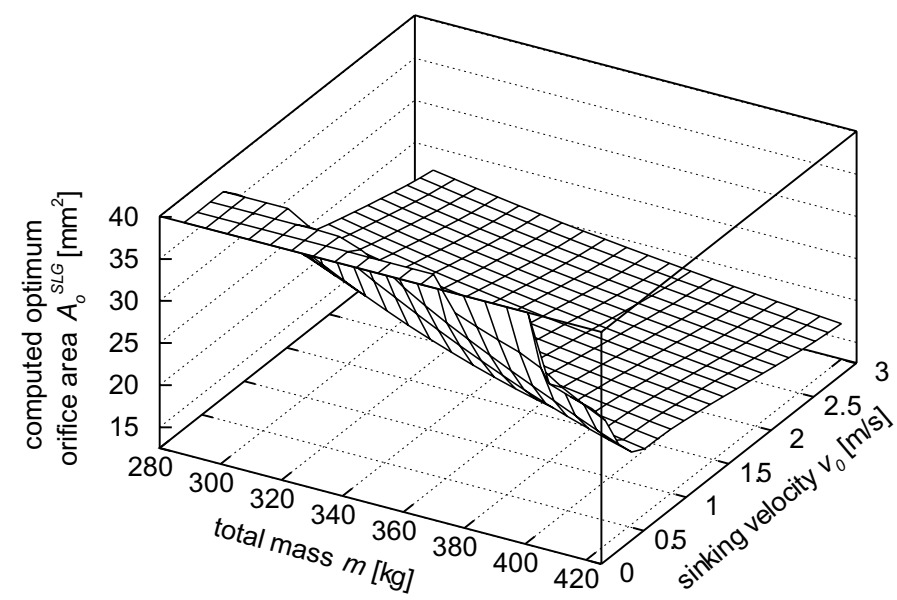

Fig. 7. Semi-active LG: Computed dependence of the optimum discharge orifice area on the total mass $m$ and sinking velocity $v_{0}$.

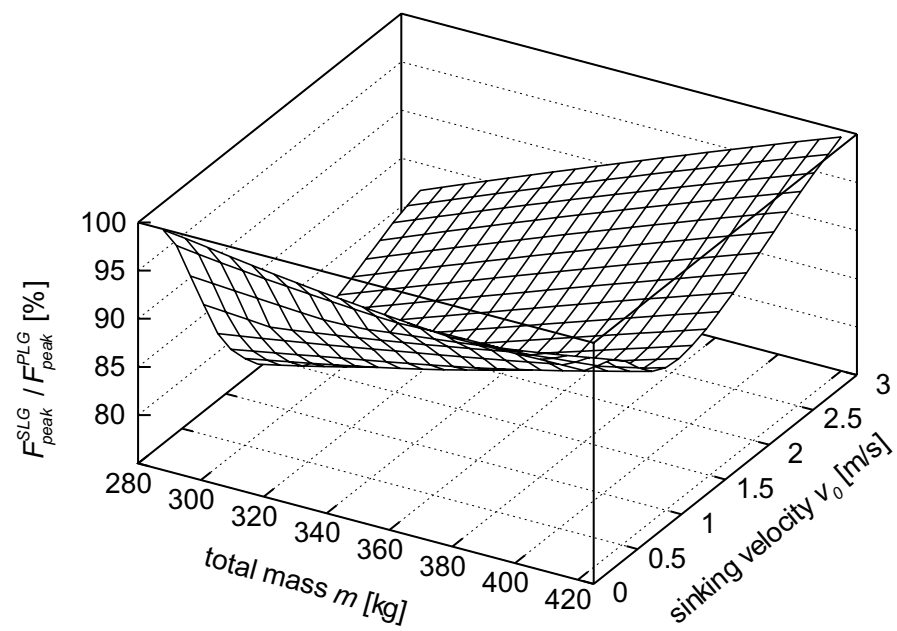

Fig. 8. SLG compared to PLG, relative improvement: Computed ratio of the peak strut force in the optimally controlled SLG to the peak strut force in PLG at the same landing conditions, in dependence on the total mass $m$ and sinking velocity $v_{0}$.

highest-energy landing scenario (i.e. at the highest mass $m_{\max }$ ),

$$
A_{o}^{V D-S L G}\left(v_{0}\right):=A_{o}^{S L G}\left(m_{\max }, v_{0}\right) .
$$

The performance of the VD-SLG must thus suffer, compared to the SLG. However, as Fig. 7 shows, the optimum orifice area is influenced more by the landing velocity than by the mass. A comparison of the performances of the VD-SLG and PLG is shown in Fig. 9, which may be compared with Fig. 8. At low sinking velocities the same effect of the initial stiffness of the air spring occurs.

\subsection{Active $L G$}

In an actively controlled LG the discharge orifice area $A_{o}$ is actively modified during the strut compression phase. The equations in Section 2 directly relate the total strut force $F_{S}$ to $A_{o}$ by:

$$
F_{S}=F_{a}+F_{f}+F_{d}+\frac{1}{2} \operatorname{sign}(\dot{s}) \frac{\rho A_{h}^{3}}{C_{d}^{2} A_{o}^{2}} \dot{s}^{2} .
$$




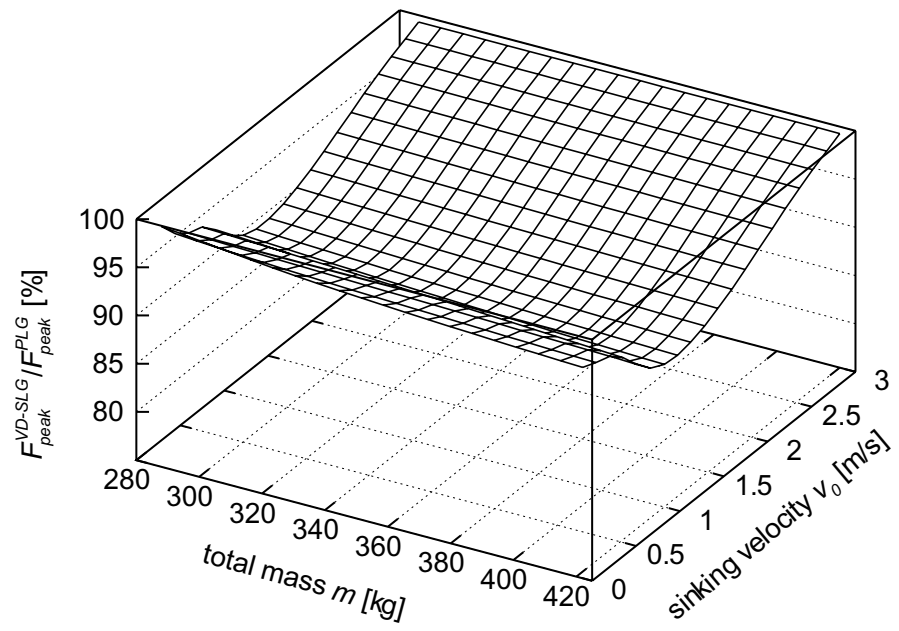

Fig. 9. VD-SLG compared to PLG, relative improvement: Computed ratio of the peak strut forces in the optimally controlled VD-SLG and PLG at the same landing conditions, in dependence on the total mass $m$ and sinking velocity $v_{0}$.

Hence, if instantaneous control is assumed, an obvious method to keep the total strut force $F_{S}$ at a desired limit value $F_{\text {limit }}$ is to actively set $A_{o}$ during the compression phase according to

$$
A_{o}^{2}= \begin{cases}A_{o(\max )}^{2} & \text { if } F_{\text {limit }} \leqslant F_{a}+F_{f}+F_{d} \\ \max \left(A_{o(\min )}^{2}, \min \left(A_{o(\max )}^{2}, \frac{\rho}{2} \frac{A_{h}^{3}}{C_{d}^{2}} \frac{\dot{s}^{2} \operatorname{sign}(\dot{s})}{F_{\text {limit }}-F_{a}-F_{f}-F_{d}}\right)\right) & \text { otherwise }\end{cases}
$$

where the first value serves the instantaneous minimization of $F_{S}$ in case it inevitably exceeds $F_{\text {limit }}$. According to Eq. (9), at the very beginning of the strut motion, when the total strut force $F_{S}$ is still low, the discharge orifice area $A_{o}$ is set to $A_{o(\min )}$ and stay so until $F_{S}$ attains $F_{\text {limit }}$. Thereafter $A_{o}$ is actively controlled within the given limits until the decompression phase begins. Therefore, the active approach of Eq. (9) requires optimization of the peak force with respect to only one parameter $F_{\text {limit }}$, which has to be performed for each landing conditions defined by $m$ and $v_{0}$.

However, Eq. (9) is only an approximation to the optimum active control. A finer control strategy applied at the beginning of the compression phase, before attaining $F_{\text {limit }}$, could further increase the efficiency of the strut and reduce the peak force. To come closer to the optimum strategy, the strut can be softened at the beginning of the impact by setting the initial discharge orifice area to a given value $A_{\mathrm{o} \text { (ini) }}$. The active control of Eq. (9) begins first when the force limit $F_{\text {limit }}$ has been attained. In a real LG it will also reduce the initial tire - runway friction, allow for a gradual wheel spin-up and reduce the spring-back effects. This resulted in optimization with respect to two parameters: (1) initial area of the discharge orifice $A_{\mathrm{o}(\mathrm{ini})}$; (2) desired strut force limit $F_{\text {limit }}$, which triggers and controls the phase of active control according to Eq. (9).

Figure 10 shows the relative improvement in comparison to the PLG. The advantage of the ALG over SLG (Fig. 8) at standard landing conditions (low sinking speed) amounts to not more than 3\% and is rather insignificant. However, at the highest-energy landing conditions it attains the maximum of approx. $9 \%$, which is significantly better than the semi-active strategy.

\subsection{Velocity-driven active $L G$}

Similarly to VD-SLG, a VD-ALG can be considered to study the limiting case of the practical scenarios when the mass $m$ is not known before the landing and should be thus assumed to be the maximum $m_{\max }$ :

$$
\begin{aligned}
& A_{\mathrm{o}(\mathrm{ini})}^{V D-A L G}\left(v_{0}\right):=A_{\mathrm{o}(\mathrm{ini})}^{A L G}\left(m_{\max }, v_{0}\right), \\
& F_{\text {limit }}^{V D-A L G}\left(v_{0}\right):=F_{\text {limit }}^{A L G}\left(m_{\max }, v_{0}\right) .
\end{aligned}
$$




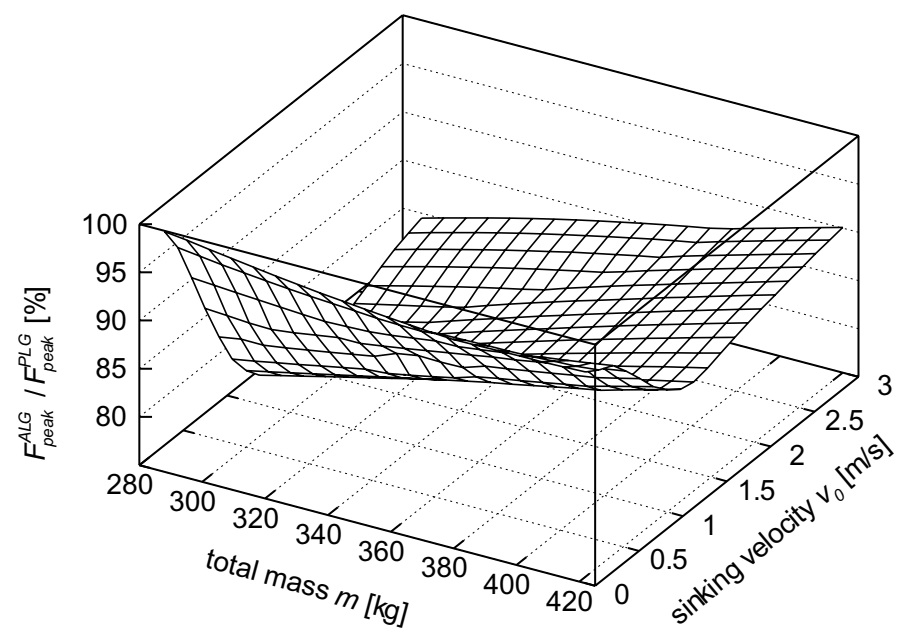

Fig. 10. ALG compared to PLG, relative improvement: Computed ratio of the peak strut forces in the optimally controlled ALG and PLG at the same landing conditions, in dependence on the total mass $m$ and sinking velocity $v_{0}$.

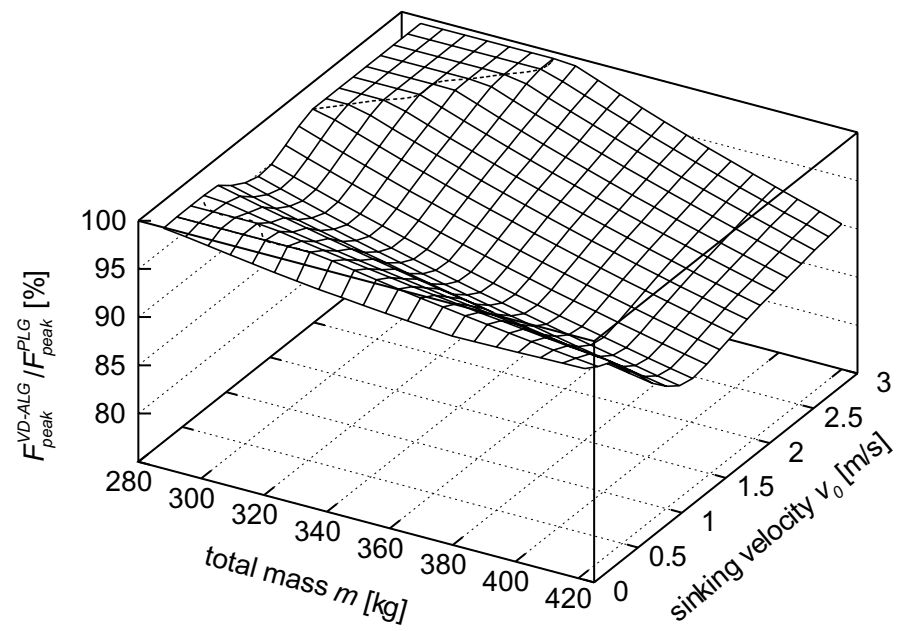

Fig. 11. VD-ALG compared to PLG, relative change: Computed ratio of the peak strut forces in the optimally controlled VD-ALG and PLG at the same landing conditions, in dependence on the total mass $m$ and sinking velocity $v_{0}$; the contour line marks the $100 \%$ level.

Figure 11 compares the performances of the VD-ALG and PLG. At low landing mass the peak force can be even higher than in the standard PLG, which renders the pure VD-ALG strategy useless.

\subsection{Example simulations}

All sample simulations presented in this section are based on the landing conditions $m=350 \mathrm{~kg}$ and $v_{0}=$ $1.5 \mathrm{~m} / \mathrm{s}$, which are taken as examples and lie approximately in the middle of the design range (see Eq. (2)).

Figure 12 compares the computed strut forces in the PLG and SLG during the first $200 \mathrm{~ms}$ of the landing process. Figure 13 shows the forces in the ALG along with the details of the applied active control. Two small temporary decreases of the total strut force at approx. $60 \mathrm{~ms}$ and $100 \mathrm{~ms}$ are results of attaining the lower limit $A_{\mathrm{o}(\mathrm{min})}$ imposed on the orifice area (see the bottom plot of the active control). Notice how the pneumatic and hydraulic force peaks, which are unequal in the PLG, are made equal in the SLG and additionally leveled in the ALG. Further reduction of the peak strut force is possible only by increasing the force growth rate in the first $25 \mathrm{~ms}$ by decreasing the initial orifice area $A_{\mathrm{o}(\mathrm{ini})}$. However, in a real LG this would considerably increase the tire - runway friction and the 


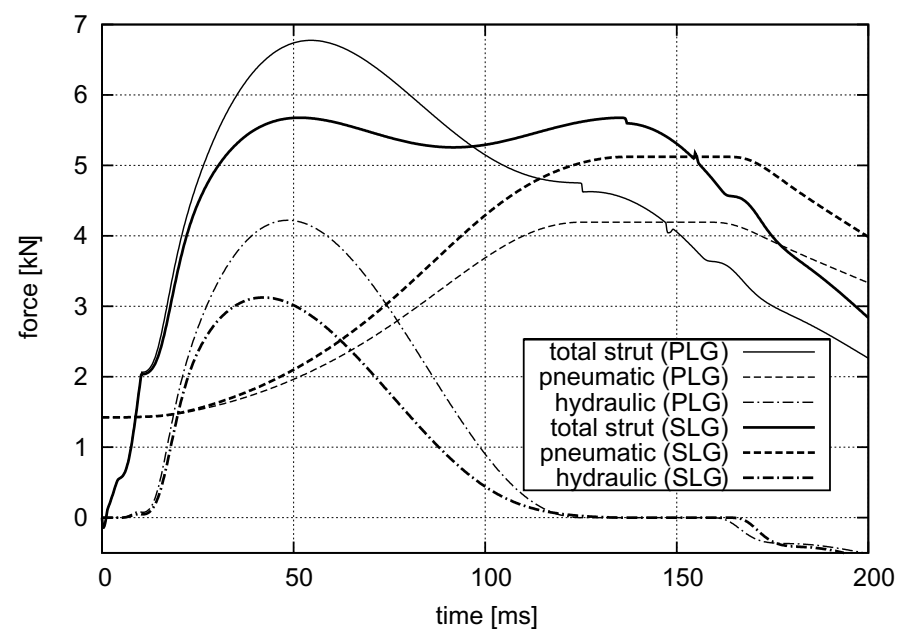

Fig. 12. Comparison of computed pneumatic, hydraulic and total strut forces in PLG and SLG for $m=350 \mathrm{~kg}$ and $\varpi=1.5 \mathrm{~m} / \mathrm{s}$.

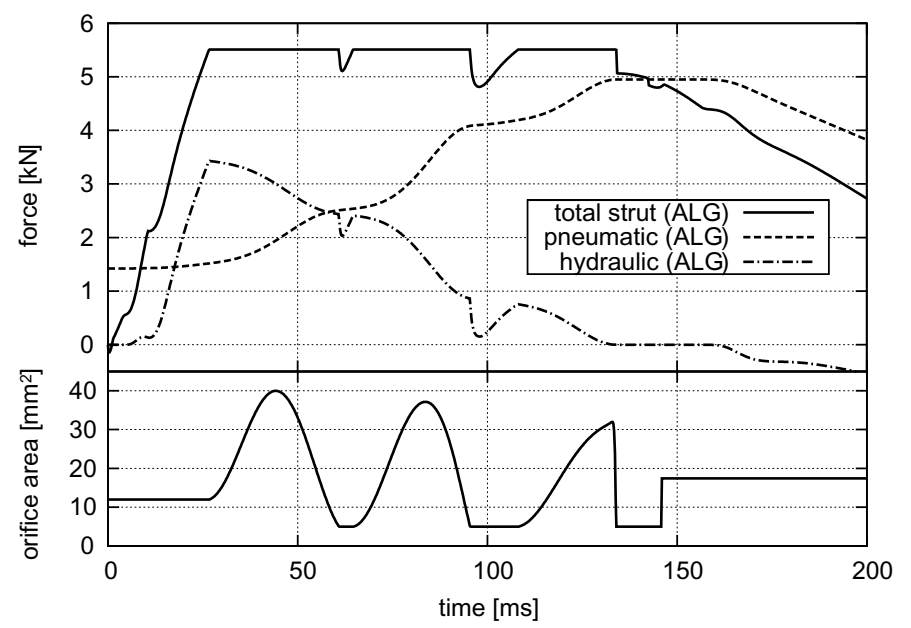

Fig. 13. Computed pneumatic, hydraulic and total strut forces in ALG, and active control for $m=350 \mathrm{~kg}$ and $v_{0}=1.5 \mathrm{~m} / \mathrm{s}$.

spring-back effect. It would also require a substantial increase of the orifice area upper limit $A_{\mathrm{o}(\max )}$ to maintain the constant force level in the subsequent $25 \mathrm{~ms}$ (see the first peak of the active control in Fig. 13). The plots of the strut force versus strut deflection for the four considered control strategies are compared in Fig. 14.

\section{Potential for improvement}

\subsection{Air spring influence}

A typical landing scenario involves a low sinking velocity, see Fig. 15. However, the investigated control strategies reveal improvements only for medium-to-high sinking velocities, see Figs 8, 9 and 10. This is due to the effect of the pre-stressed air spring and the lift force: to compress the strut further than the delimiting force acting range $l_{d}=0.5 \mathrm{~mm}$, the strut force has to overcome the joint effect of the pneumatic and friction forces, which amounts to $1983 \mathrm{~N}$ and is comparable to the peak force at $v_{0}=0 \mathrm{~m} / \mathrm{s}$, which was computed to be $1993 \mathrm{~N}-2179 \mathrm{~N}$, depending on the mass. Therefore, at low sinking velocities the strut is being barely compressed and there is practically no 
Table 2

Assumed cumulative occurrences of sinking velocities per 1000 landings

\begin{tabular}{cccc}
\hline $\begin{array}{c}\text { Sinking } \\
\text { velocity } v_{0}[\mathrm{~m} / \mathrm{s}]\end{array}$ & $\begin{array}{c}\text { Cumulative } \\
\text { occurrences }\end{array}$ & $\begin{array}{c}\text { Sinking } \\
\text { velocity } v_{0}[\mathrm{~m} / \mathrm{s}]\end{array}$ & $\begin{array}{c}\text { Cumulative } \\
\text { occurrences }\end{array}$ \\
\hline 0.00 & 1000.0 & 1.54 & 63.0 \\
0.15 & 994.6 & 1.70 & 33.8 \\
0.31 & 925.6 & 1.85 & 17.7 \\
0.46 & 811.3 & 2.00 & 9.7 \\
0.62 & 669.6 & 2.16 & 4.7 \\
0.77 & 518.8 & 2.31 & 2.5 \\
0.93 & 380.2 & 2.47 & 1.6 \\
1.08 & 260.3 & 2.62 & 1.0 \\
1.23 & 172.9 & 2.78 & 0.6 \\
1.39 & 108.4 & 2.93 & 0.3 \\
\hline
\end{tabular}

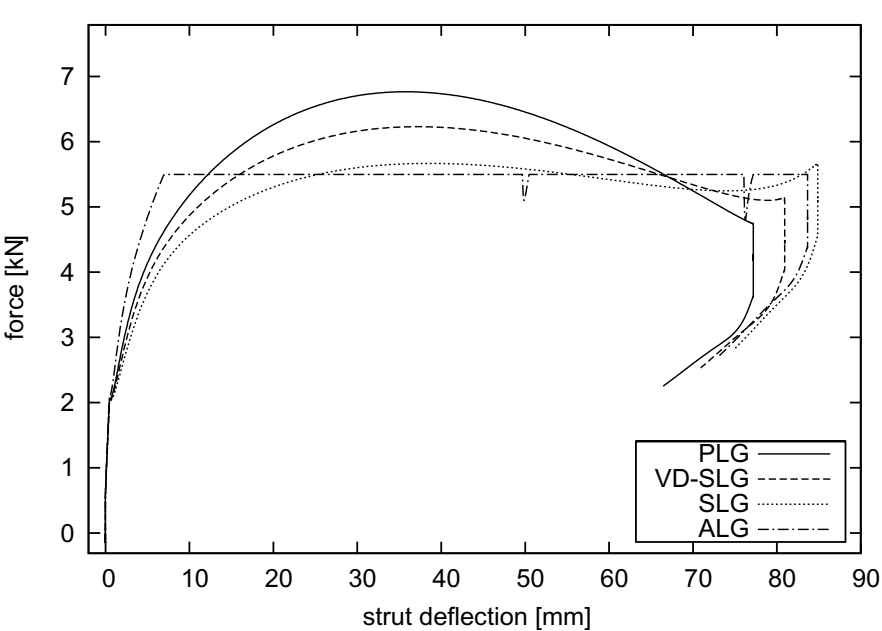

Fig. 14. Strut force versus deflection in PLG, VD-SLG, SLG and ALG for $m=350 \mathrm{~kg}$ and $v_{0}=1.5 \mathrm{~m} / \mathrm{s}$.

hydraulic force to be controlled. As a result no strategy based on hydraulic force control can yield improvement at low sinking velocities. This is, however, not necessary, since the static runway loading is considerably higher than the landing peak force at low sinking velocities. This is due to the lift factor $L=0.667$, which occurs in Eq. (1) and disappears in static or taxiing conditions. Therefore, the (semi)-active control strategies can in fact be considered necessary only in the cases when the peak force in the PLG is significant, i.e. exceeds the static loading, $F_{\text {peak }}^{P L G}\left(m, v_{0}\right)>m g$. This occurs at higher sinking velocities only; the limiting velocity ranges from $0.54 \mathrm{~m} / \mathrm{s}$ to $0.85 \mathrm{~m} / \mathrm{s}$, depending on the landing mass $m$.

\subsection{Mean and median peak strut force}

Figures 8 to 11 compare the performance of the discussed LG types for each design landing condition separately. An overall comparison is possible by statistical means if the probability distributions of landing conditions are defined. The initial sinking velocity $v_{0}$ and the total mass $m$ are assumed to be independent. To ease the statistical computations, their ranges Eq. (2) have been discretized into 20 equally spaced values. The distribution of the landing mass has been assumed to be uniform in the whole range of $288 \mathrm{~kg}-422 \mathrm{~kg}$. The assumed discretized distribution of the initial sinking velocity $v_{0}$ is listed in Table 2 (cumulative occurrences) and illustrated in Fig. 15 (occurrences).

Table 3 compares the performances of the four LG types in terms of the expected and median peak strut forces. Two cases have been considered, unconditional and conditional:

1. All landing conditions have been taken into accounts, unconditional $E\left[F_{\text {peak }}\right]$ and median $\left[F_{\text {peak }}\right]$ have been computed for the four control strategies considered. 
Table 3

Performance of four LG control strategies, a statistical comparison. Case 1: Unconditional values (all landing scenarios); Case 2: Conditional values (landings with the PLG peak strut force exceeding the static load

\begin{tabular}{cccccc}
\hline \multirow{3}{*}{ LG type } & \multicolumn{2}{c}{ Peak strut force } & & \multicolumn{2}{c}{ Relative improvement } \\
\cline { 2 - 3 } \cline { 5 - 6 } & Expected & Median & & Expected & Median \\
& value $[\mathrm{kN}]$ & value $[\mathrm{kN}]$ & & value [\%] & value [\%] \\
\hline
\end{tabular}

\begin{tabular}{lccrr}
\hline \multicolumn{5}{l}{ Case 1: Unconditional (all landing scenarios) } \\
PLG & 3.890 & 3.527 & - & - \\
VD-SLG & 3.618 & 3.284 & 7.0 & 6.9 \\
SLG & 3.386 & 2.992 & 12.9 & 15.2 \\
ALG & 3.331 & 2.959 & 14.4 & 16.1 \\
Case 2: Conditional $\left(F_{\text {peak }}^{P L G}>m g\right)$ & & \\
PLG & 4.962 & 4.613 & - & - \\
VD-SLG & 4.565 & 4.232 & 8.0 & 8.3 \\
SLG & 4.202 & 3.878 & 15.3 & 15.9 \\
ALG & 4.106 & 3.790 & 17.2 & 17.8 \\
\hline
\end{tabular}

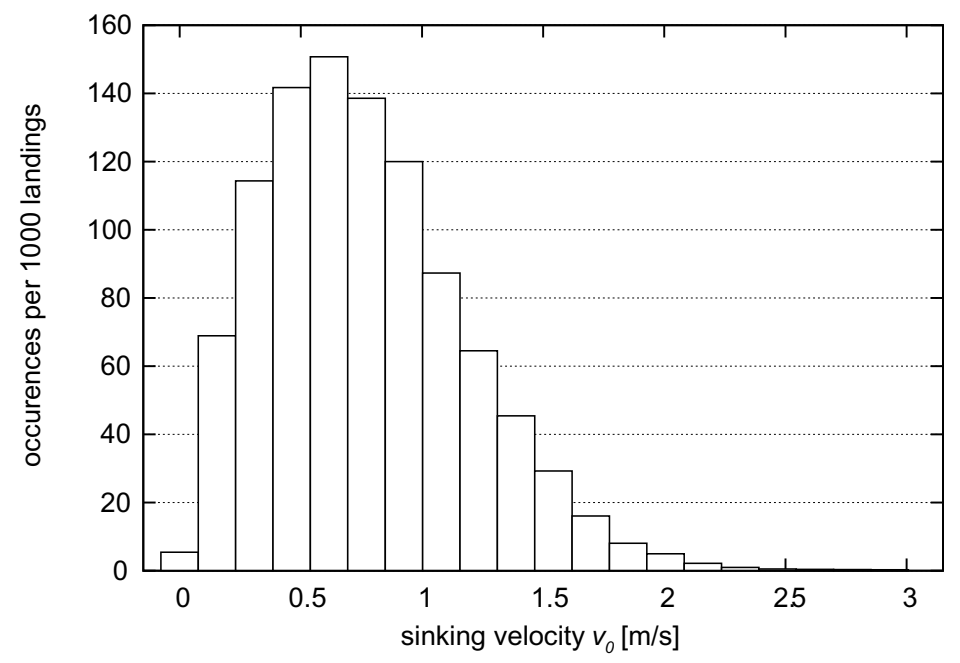

Fig. 15. Assumed occurrences of sinking velocities per 1000 landings.

2. Only landings with the PLG peak strut force exceeding the static load have been taken into account. This case reports on the statistical reduction of significant peaks and leads to conditional probability distributions, expected values and medians

$$
E\left[F_{\text {peak }} \mid F_{\text {peak }}^{\mathrm{PLG}}>m g\right], \text { median }\left[F_{\text {peak }} \mid F_{\text {peak }}^{\mathrm{PLG}}>m g\right] .
$$

\subsection{Safe sinking velocity range}

The described control strategies decrease the peak strut force, hence allow the sinking velocity range to be extended even beyond $v_{0(\max )}=2.93 \mathrm{~m} / \mathrm{s}$ without exceeding the peak strut force limit $F_{\max }$. Figure 16 compares, in terms of the landing mass $m$ at three control strategies (PLG, SLG, ALG), the maximum safe sinking velocities $\hat{v}$, which are defined by an implicit relation $F_{\text {peak }}(\hat{v}, m)=F_{\max }$. The velocity-driven semi-active strategy (VD-SLG) has been skipped, since it assumes no information about the landing mass $m$ and is hence bound by $v_{0(\max )}=2.93 \mathrm{~m} / \mathrm{s}$, which occurs at $m_{\max }$. 


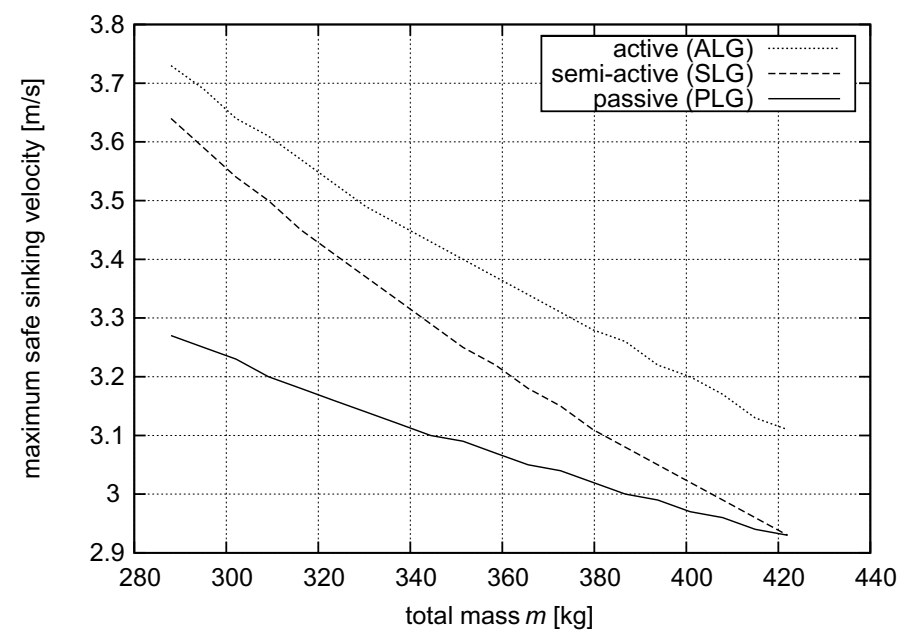

Fig. 16. Maximum safe sinking velocity at three control strategies in terms of the total landing mass.
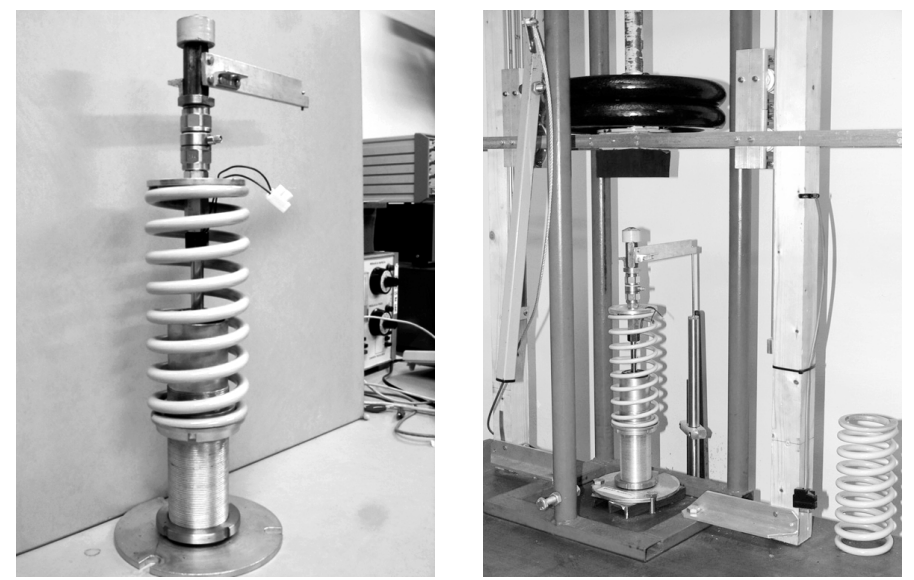

Fig. 17. (left) Laboratory model of Adaptive Impact Absorber (AIA); (right) AIA mounted on the laboratory drop test rig.

\section{Experiment}

The results of the numerical analysis were confirmed experimentally by means of a small laboratory demonstrator. The demonstrator has been tested in the passive, semi-active and active control modes and the results have been compared with the aim of (1) confirming the feasibility of the proposed control strategies and (2) assessing experimentally the corresponding reduction of the peak forces.

\subsection{Testing stand}

The adaptive landing gear was substituted in the experiment with an intentionally designed, lab-scale Adaptive Impact Absorber (AIA). The adaptability of the AIA was realized by means of a variable viscous damping force, obtained with a magnetorheological (MR) fluid. The AIA was composed of a magnetorheological damper and a coil spring, see Fig. 17 (left). A dedicated control unit, developed in the FPGA technology, allowed generation of the desired level of the damping force $(500 \mathrm{~N}-2000 \mathrm{~N})$ within rigorous time restrictions: the time delay was less than $3 \mathrm{~ms}$ [27].

The tests were performed on a small drop test device, designed and developed in laboratory, see Fig. 17 (right). The idea was to realize the same scheme of impact excitation and thus to ensure its compatibility with full-scale 
Table 4

Kinetic energies used in tests

\begin{tabular}{|c|c|c|c|c|c|c|c|c|c|c|}
\hline \multirow{2}{*}{\multicolumn{2}{|c|}{$\begin{array}{l}\text { Kinetic } \\
\text { energy }[\mathrm{J}]\end{array}$}} & \multicolumn{9}{|c|}{ Sinking velocity $[\mathrm{m} / \mathrm{s}]$} \\
\hline & & 1.46 & 1.30 & 1.10 & 1.00 & 0.95 & 0.85 & 0.79 & 0.58 & 0.40 \\
\hline & 67 & 71.41 & 56.62 & 40.54 & 33.50 & 30.23 & 24.20 & 20.91 & 11.27 & 5.36 \\
\hline & 57 & 60.75 & 48.17 & 34.49 & 28.50 & 25.72 & 20.59 & 17.79 & 9.59 & 4.56 \\
\hline Mass & 47 & 50.09 & 39.72 & 28.44 & 23.50 & 21.21 & 16.98 & 14.67 & 7.91 & 3.76 \\
\hline \multirow[t]{4}{*}[\mathrm{kg}]{} & 37 & 39.43 & 31.27 & 22.39 & 18.50 & 16.70 & 13.37 & 11.55 & 6.22 & 2.96 \\
\hline & 27 & 28.78 & 22.82 & 16.34 & 13.50 & 12.18 & 9.75 & 8.43 & 4.54 & 2.16 \\
\hline & 17 & 18.12 & 14.37 & 10.29 & 8.50 & 7.67 & 6.14 & 5.30 & 2.86 & 1.36 \\
\hline & 7 & 7.46 & 5.92 & 4.24 & 3.50 & 3.16 & 2.53 & 2.18 & 1.18 & 0.56 \\
\hline
\end{tabular}
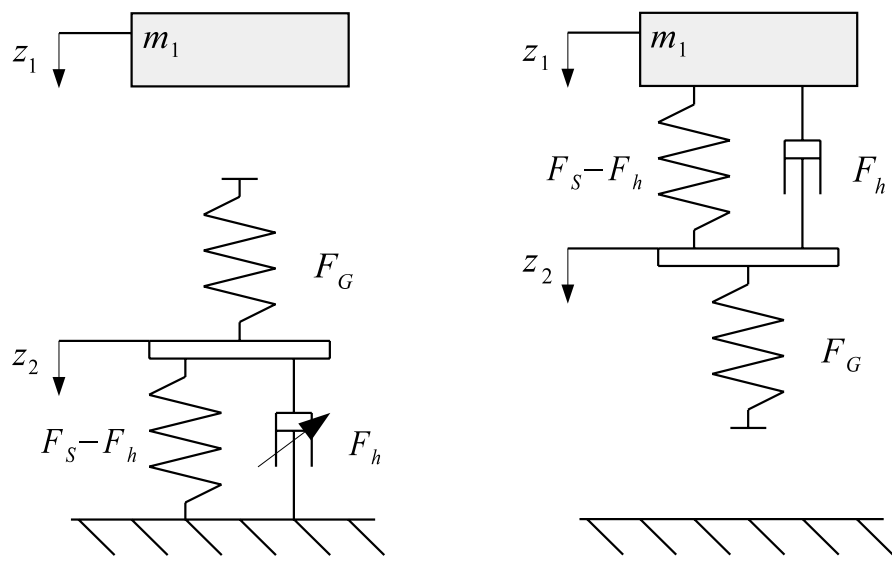

Fig. 18. Comparison of schemes of testing stands: (Left) lab-scale; (right) full-scale.

testing stands dedicated to testing of landing gears. Full-scale testing stands fix the landing gears under a drop mass, which simulates a respective part of the weight of an aircraft. The test procedures include free falling drops from various heights to simulate different sinking velocities. In order to make the laboratory landing conditions more close to reality, struts are usually tested with variable circumferential speed of the wheel and, in the case of main landing gears, with various attitude angles (up to 15 degrees). Moreover, full-scale testing stands are equipped with a simulator of the lift force, which is able to generate the wing lift contribution to the landing process. For the purpose of the small, lab-scale experiment, the testing procedure was simplified in the following points:

1. The tests were conducted only in the vertical position of the adaptive impact absorber;

2. The tire of the landing gear was substituted by a bumper made of solid rubber;

3. The absorbing element was not mounted to the free falling mass but fixed in the vertical position on the foundation plate;

4. The lift force was not simulated.

Due to the simplifications, the friction forces generated on the sliding surfaces of the damper were much lower compared to real-world landing gear. The rubber element had relatively stiffer characteristic in comparison to the characteristic of a pneumatic tire. Neglecting of the lift force had an influence on the inertial balance of the system. However, from the mechanical point of view, both systems are analogous (Fig. 18) and the time limitations for the control and actuation systems are the same.

The test program consisted of 567 drop tests. The procedure included drop tests in 63 cases of impact energy $(0.6 \mathrm{~J}-70 \mathrm{~J})$, which are listed in Table 4 . In each case, the drops were conducted for three tested modes of operation and repeated three times to guarantee the proper repeatability.

\subsection{Control strategies}

To test the passive control strategy, the AIA was assumed to behave as a conventional, passive landing gear, and optimized to operate properly under the maximum considered impact energy. A constant level of the control 


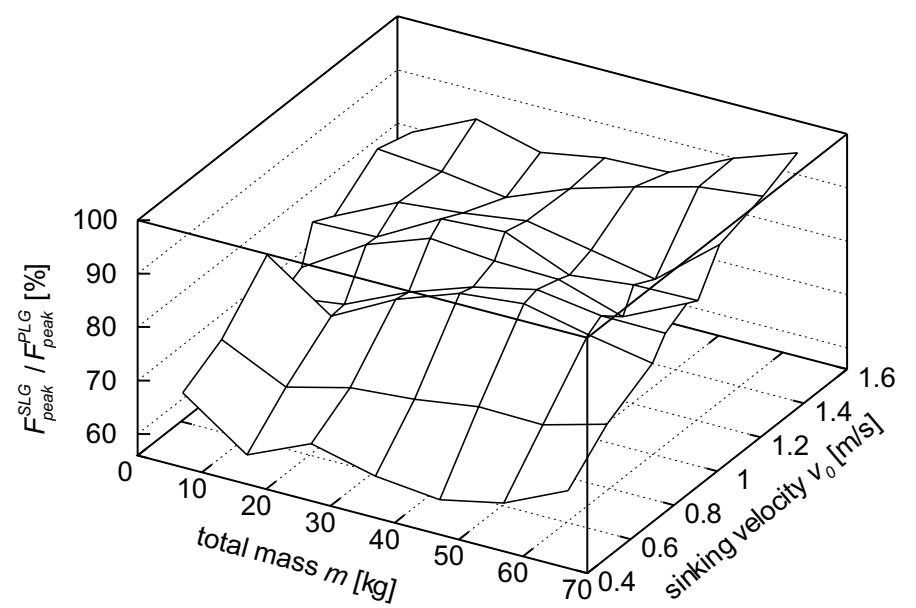

Fig. 19. Semi-active control experimentally compared to passive control: ratio of the measured peak dynamic forces, cf. Fig. 8 .

signal was determined, which allowed the peak dynamic force to be minimized without reaching the full piston stroke. Further on, the tests were conducted for the full range of the impact energies with the determined level of the damping characteristics. The peak dynamic force was measured and stored to serve as a reference for assessment of the effectiveness of the proposed adaptive control strategies.

In the semi-active mode, the constant damping control signal was adjusted separately in each particular case of the impact, in dependence on its kinetic energy. The semi-activity of the system was thus defined as using an open loop control only. The control procedure consisted of: (1) determination of the sinking velocity and the mass of the falling object and (2) generation of the corresponding optimum level of the control signal and the adaptation of the system. Figure 19 depicts the relative value of the measured peak dynamic force at the semi-active strategy in comparison to the peak force at the passive strategy and the same impact energy. The results are similar to the numerical results depicted in Fig. 8, the difference is due to the lift force present in the numerical computations and neglected in the experiment, which effectively decreases the weight of the drop mass but does not affect its inertial behavior (mass). The improvement is most significant at small impact velocities. An overall peak force reduction is approx. $20 \%$.

The active control strategy was realized in a closed loop control with the vertical acceleration of the structure as the feedback signal [27,36]. The control sequence consisted of: (1) recognition of the energy of the impact; (2) initial adaptation of the system; (3) execution of the feedback control strategy. The recognition of the impact energy was realized within $2 \mathrm{~ms}$ before the impact moment. To measure the sinking velocity a photo sensor was used, while the drop mass was assumed to be known. The objective of the closed loop control strategy was to adhere to a predefined value of the deceleration of the structure, which was determined in accordance to the recognized impact energy. Figure 20 depicts the relative value of the measured peak dynamic force in comparison to the peak force at the passive strategy and the same impact energy. The approximate gain with respect to the semi-active strategy (Fig. 19) is on the level of 5\%. The relative improvement increases with the impact energy, which is similar to the numerical results, see Fig. 10.

\subsection{Example measurements}

Figures 21 and 22 compare the plots of measured force $F_{S}$ versus strut deflection $s$, which clearly illustrate the effects of the tested control strategies. The advantage of the semi-active and active modes over the passive is clear in both cases: the peak dynamic force has been considerably reduced. The advantage of the active strategy over the semi-active is much less pronounced. However, the active strategy, besides decreasing the peak dynamic force, which was the objective here, also significantly decreased the maximum piston strokes needed to complete the dissipation process. With the active strategy the energy is thus dissipated on a shorter distance. The displacements of the pistons were reduced by $15 \%$ on average, which significantly enlarges the energy dissipation potential of the AIA. 


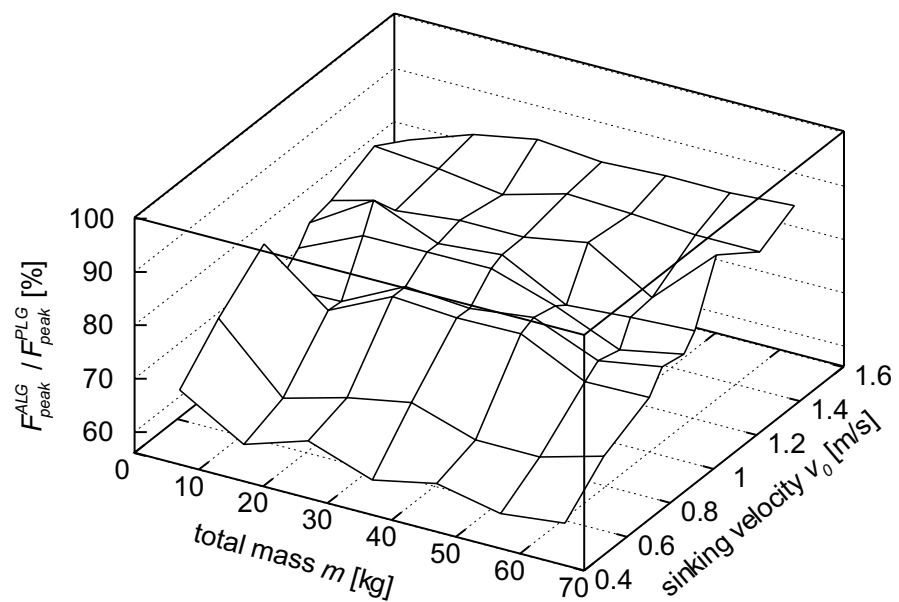

Fig. 20. Active control experimentally compared to passive control: ratio of the measured peak dynamic forces, cf. Fig. 10.

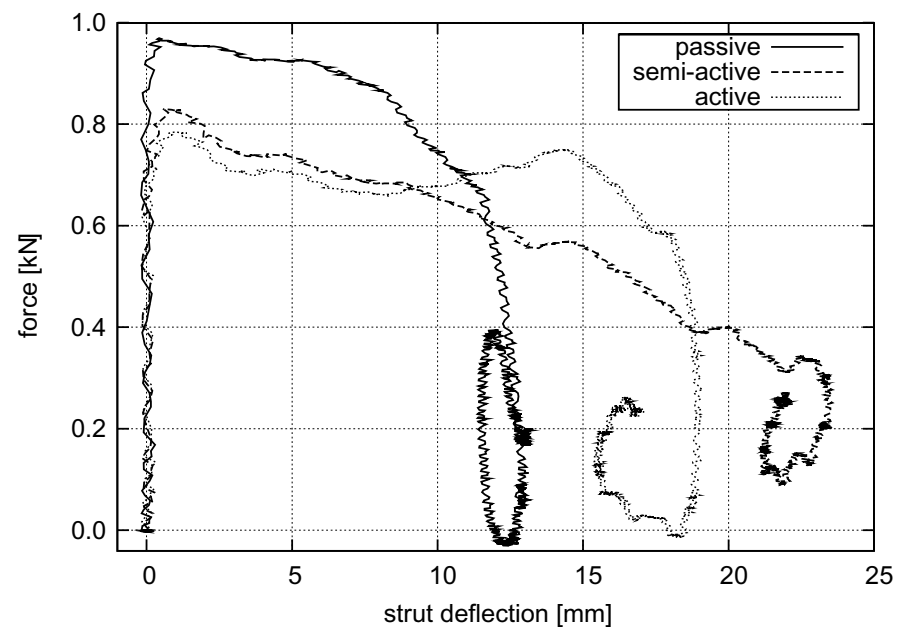

Fig. 21. Measured force versus deflection at the passive, semi-active and active control strategy for $m=37 \mathrm{~kg}$ and $v_{0}=0.79 \mathrm{~m} / \mathrm{s}$ (drop height $32 \mathrm{~mm})$.

\section{Conclusions}

All numerical simulations in this paper have been based on the I-23 nose LG, other LGs could lead to slightly different numerical results. Nevertheless, the most important findings are confirmed in the experimental tests and can be summarized as follows:

1. The superiority of the adaptive paradigm over standard passive solutions is clearly confirmed both by numerical simulations and in laboratory tests. The modeled adaptive LG excels the modeled passive LG by $6.9 \%-17.8 \%$ in terms of the median peak strut force. Up to $37 \%$ improvement has been obtained in laboratory tests, with an average of $20 \%$.

2. The relative improvement between the modeled semi-active and active control strategies seems to be statistically rather insignificant (1\%-2\% in terms of the median peak strut force). However, the advantage of the active strategy increases considerably with the sinking velocity and landing mass to attain the maximum of approx. $10 \%$ at the highest-energy design landing conditions (at which the semi-active strategy shows no improvement to the passive), in simulation as well as in experiment. Therefore, implementation of an active control system can: 


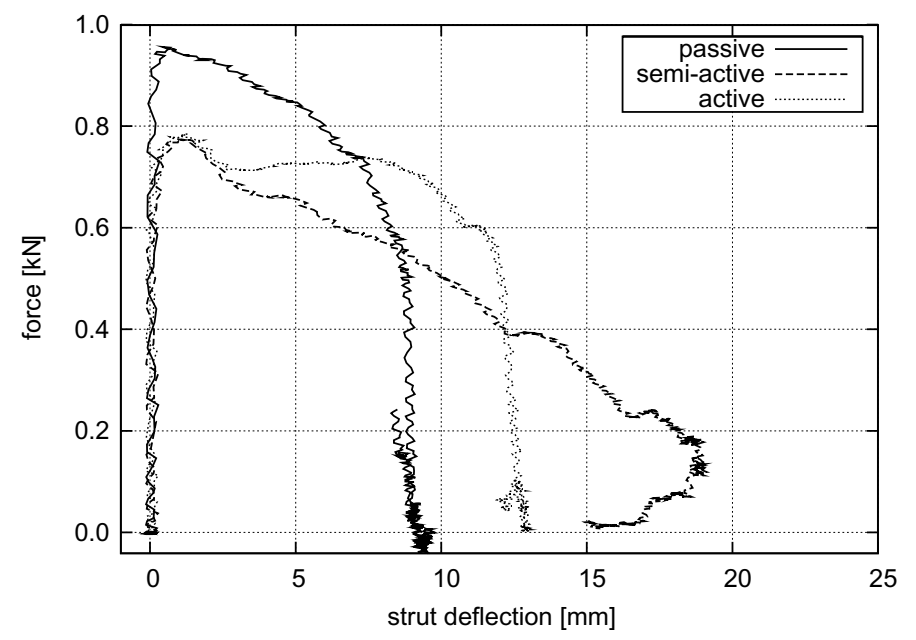

Fig. 22. Measured force versus deflection at the passive, semi-active and active control strategy for $m=27 \mathrm{~kg}$ and $v_{0}=0.85 \mathrm{~m} / \mathrm{s}$ (drop height $37 \mathrm{~mm})$.

- significantly mitigate the peak strut force transferred to the aircraft structure and the potential structural damage at the most demanding landing conditions (high mass and sinking velocity), which rarely occur but are the most dangerous;

- provide the safety margin by increasing the limiting sinking velocity, especially at high landing masses.

3. If the landing mass is not known exactly, it has to be overestimated for safety reasons. However, simulations show that at least partial knowledge of the mass is necessary to obtain significant improvement over the passive control scheme: If the mass is not known at all, the average profit (in terms of the median peak strut force) of the semi-active control strategy is reduced from 15\%-16\% (SLG) to approx. 7\%-8\% (VD-SLG), whereas the active strategy (VD-ALG) is useless.

\section{Acknowledgments}

The authors acknowledge the support through the FP6 EU project ADLAND [4] (IST-FP6-2002-Aero-1-502793STREP) and thank all its participants: Institute of Fundamental Technological Research (Poland), EADS Deutschland GmbH - Military Aircraft (Germany), Polskie Zakłady Lotnicze (Poland), Institute of Aviation (Poland), Fraunhoffer Institute für Silicatforschung (Germany), CEDRAT Technologies (France), University of Sheffield (U.K.) and Messier-Dowty (France). The authors acknowledge also the support through the Polish Research Project INTEGRA (Nr R10 005 02, Ministry of Science and Higher Education) and are grateful to Mr. Wojciech Kowalski (Institute of Aviation) for providing the technical specifications and the test results of I-23 nose landing gear.

\section{References}

[1] Federal Aviation Regulations (FAR), Part 23 - Airworthiness Standards: Normal, Utility, Acrobatic and Commuter Category Airplanes.

[2] J.R. McGehee and H.D. Carden, Analytical investigation of the landing dynamics of a large airplane with a load-control system in the main landing gear. Technical Report 1555, NASA, 1979.

[3] G. Mikułowski and J. Holnicki-Szulc, Adaptive Aircraft Shock Absorbers, In 3rd European Conference on Structural Control, 3ECSC, July 2004.

[4] Adaptive Landing Gears for Improved Impact Absorption, ADLAND, EU FP6 project IST-FP6-2002-Aero-1-502793-STREP. http://smart.ippt.gov.pl/adland.

[5] N.S. Currey, Aircraft Landing Gear Design: Principles and Pratices, AIAA, 1988.

[6] B. Milwitzky and F.E. Cook, Analysis of landing gear behaviour. Technical Report 1154, NACA, 1953.

[7] J.H. Walls, An experimental study of orifice coefficents, internal strut pressures, and loads on a small oleo-pneumatic shock strut. Technical note 3426, National Advisory Comittee for Aeroanutics, 1955. 
[8] A.W. Hall, R.H. Sawyer and J.M. McKay, Study of groud-reaction forces measured during landing impacts of a large airplane. Technical note 4247, National Advisory Committee for Aeronautics, May 1958.

[9] W. Flügge, Landing-gear impact Technical note 2743, National Advisory Committee for Aeronautics, October 1952.

[10] J.E. Wignot, P.C. Durup and M.A. Gamon, Design Formulation and Analysis of an Active Landing Gear, AFFDL-TR-71-80 Vol. I, U.S. Air Force, 1971.

[11] E.K. Bender, E.F. Berkman and M. Bieber, A Feasibility Study of Active Landing Gear, AFFDL-TR-70-126, U.S. Air Force, 1971.

[12] J.R. McGehee and H.D. Carden, A mathematical model of an active control landing gear for load control during impact and roll-out. Technical Note NASA TN D-8080, NASA Langley Research Center, February 1976.

[13] I. Ross, Flightworthy active control landing gear system for a supersonic aircraft. Technical report, Hydraulic Research Textron, 1980.

[14] I. Ross and R. Edson, An electronic control for an electrohydraulic active control landing gear for the F-4 aircraft. Technical report, Hydraulic Research Textron, Inc, 1982.

[15] J.R. McGehee and R.C. Dreher, Experimental Investigation of Active Loads Control for Aircraft Landing Gear, NASA Technical Paper 2042, Langley Research Centre, 1982.

[16] J.R. McGehee and D.L. Morris, Active Control Landing Gear for Ground Load Alleviation, In AGARD Conf. Proc. 384, FMP Symposium, 1984. Toronto.

[17] W.E. Howell, J.R. McGehee, R.H. Daaugherty and W.A. Vogler, F-106b airplane active control landing gear drop test performance. NASA Technical Memorandum 102741, Langley Research Centre, November 1990.

[18] L.G. Horta, R.H. Daugherty and V.J. Martinson, Modeling and validation of a Navy A6-Intruder actively controlled landing gear system. Technical Report TP-1999-209124, NASA, 1999.

[19] L.G. Horta, R.H. Daugherty and V.J. Martinson, Actively controlled landing gear for aircraft vibration reduction. Tecnical Paper NASA99-ceas-lgh, NASA, 1999.

[20] R. Freymann, Actively damped landing gear system. In AGARD CP-484 Ref. 20, Proc. of the 71st Meeting of the AGARD Structures and Materials Panel, October 1990.

[21] Z. Lou, R.D. Ervin, C.B. Winkler and F.E. Filisko, An Electrorheologically Controlled Semi-Active Landing Gear, SAE paper 931403, Langley Research Centre, January 1993.

[22] H. Wentscher, W. Kortüm and W.R. Krüger, Fuselage Vibration Control using Semi-Active Front Gear, In Proceedings of the 81st meeting of the AGARD SMP Panel on "The design, Qualification and Maintenance of Vibration-Free Landing Gears", 1995.

[23] X. Wang and U. Carl, Fuzzy Control of Aircraft Semi-Active Landing Gear System, In Proc. of the 37th AIAA Aerospace Sciences Meeting and Exhibit, January 1999

[24] W. Krüger, Integrated Design Process for the Development of Semi-Active Landing Gears for Transport Aircraft, PhD thesis, University of Stuttgart, December 2000.

[25] G.L. Ghiringhelli, Testing of semiactive landing gear control for a general aviation aircraft, AIAA Journal of Aircraft 37(4) (2000), 606-616.

[26] G.L. Ghiringhelli and S. Gualdi, Evaluation of a landing gear semi-active control system for complete aircraft landing, Aerotecnica Missili e Spazio 83 (January 2004), 21-31.

[27] G. Mikułowski and J. Holnicki-Szulc, Adaptive landing gear concept - feedback control validation, Smart Materials and Structures 16(6) (2007), 2146-2158.

[28] D.C. Batterbee, N.D. Sims, R. Staway and Z. Wołejsza, Magnetorheological landing gear: 1. a design methodology, Smart Materials and Structures 16 (2007), 2429-2440.

[29] D.C. Batterbee, N.D. Sims, R. Staway and M. Rennison, Magnetorheological landing gear: 2. validation using experimental data, Smart Materials and Structures 16 (2007), 2441-2452.

[30] D.P. Raymer, Aircraft Design: A Conceptual Approach, AIAA education series, 1989.

[31] S.T. Chai and W.H. Mason. Landing gear integration in aircraft conceptual design. Technical Report MAD 96-09-01, MAD Center, 1996.

[32] I-23 technical specification. Institute of Aviation, Warsaw, Poland.

[33] K. Sekuła and J. Holnicki-Szulc, On-line impact load identification. submitted to International Journal of Impact Engineering, 2008.

[34] J. Holnicki-Szulc, G. Mikułowski, J. Motylewski, P. Pawłowski and Z. Wołejsza, Adaptive system for energy dissipation in landing gears (in Polish: Adaptacyjny system dyssypacji energii w podwoziu lotniczym). XXXIV Polish Symposium on Machine Diagnostics, Wegierska Górka, March 2007.

[35] D. Batterbee, N.D. Sims and R. Stanway, ADLAND report: Annex USFD-1(a): Oleopneumatic shock absorber modelling and initial MR device sizing. Technical report, University of Sheffield, 2004.

[36] G. Mikułowski and J. Holnicki-Szulc, Fast controller and control algorithms for MR based adaptive impact absorbers - force based control, Machine Dynamics Problems 30(2) (2006), 113-122. 

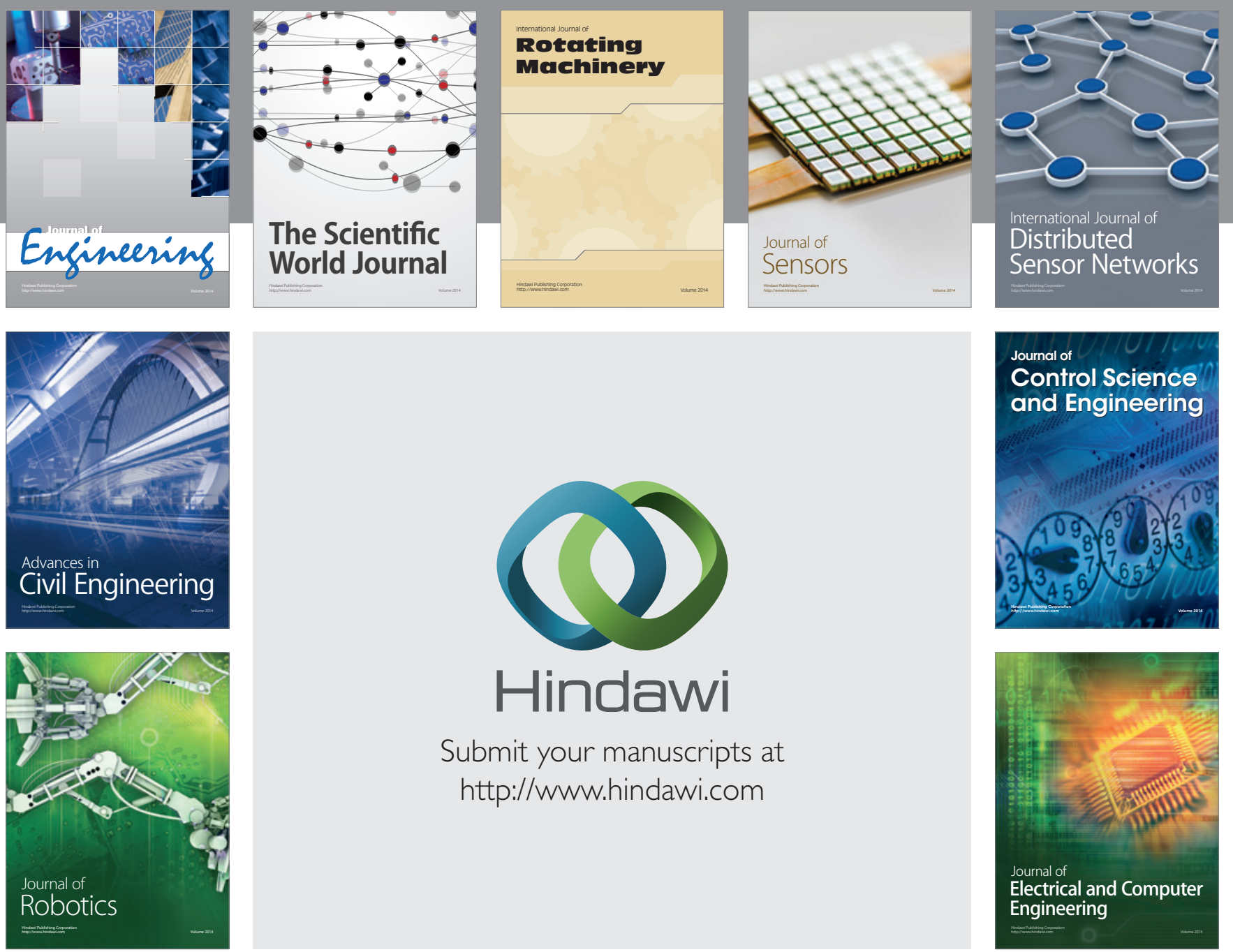

Submit your manuscripts at

http://www.hindawi.com
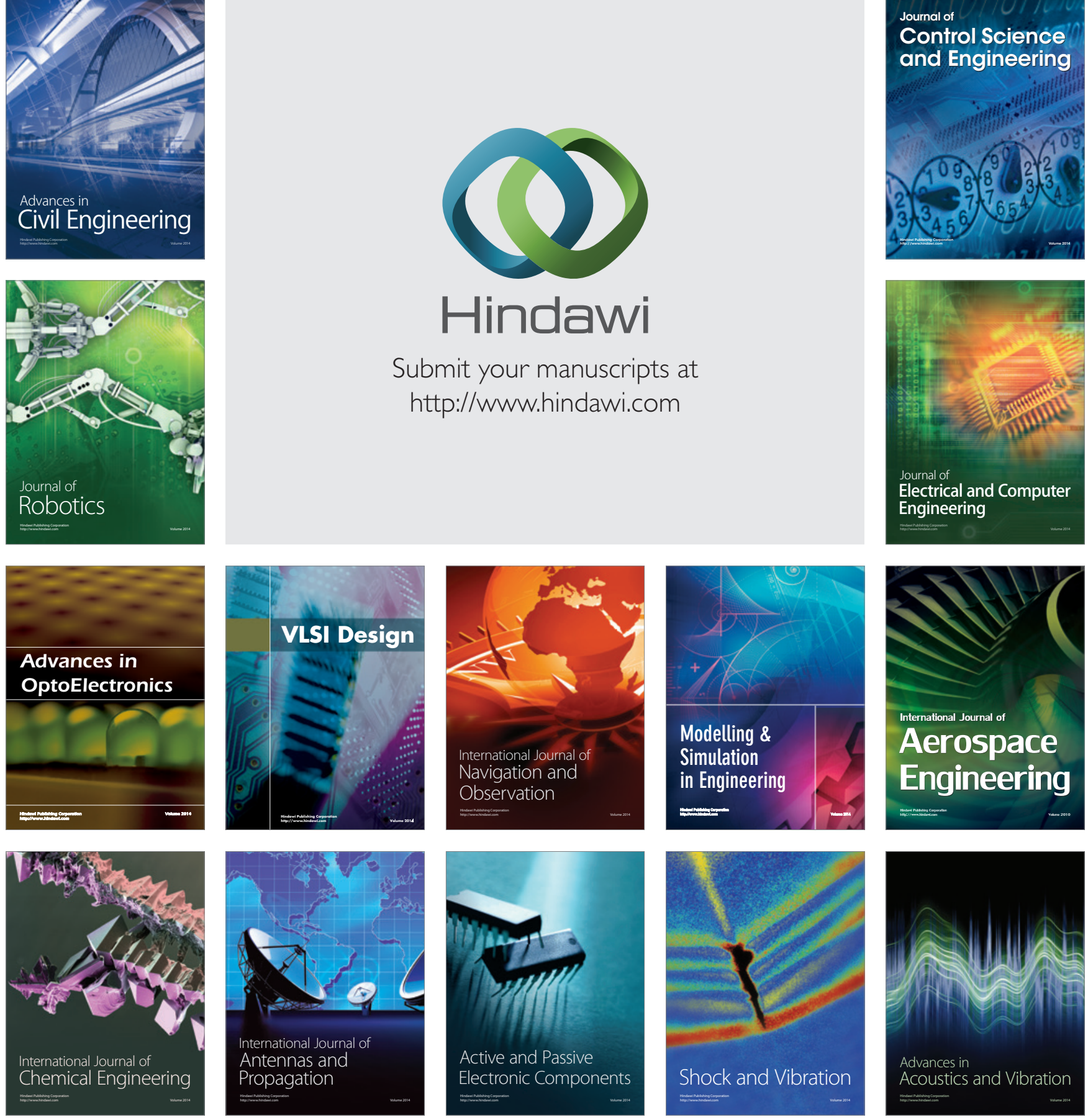